\title{
复 \\ Impactos do vírus Schmallenberg na produção de ruminantes: revisão de literatura
}

\author{
[Impacts of Schmallenberg virus in ruminant production: literature review]
}

\section{"Revisão/Review"}

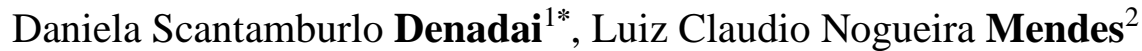

\author{
${ }^{1}$ Programa de Pós-Graduação em Ciência Animal, Faculdade de Medicina Veterinária, Universidade Estadual Paulista \\ (UNESP), Araçatuba-SP, Brasil. \\ ${ }^{2}$ Departamento de Clínica, Cirurgia e Reprodução Animal, Faculdade de Medicina Veterinária, Universidade Estadual \\ Paulista (UNESP), Araçatuba-SP, Brasil. \\ *Autor para correspondência/Corresponding author: E-mail: daniela_denadai@ hotmail.com
}

\begin{abstract}
Resumo
Objetivou-se reunir informações relevantes sobre o Schmallenberg, uma doença viral emergente no continente europeu, que foi identificada pela primeira vez na Alemanha. Abortos, malformações fetais e mortes perinatais também estão associados ao vírus, observando-se principalmente artrogripose e alterações no sistema nervoso central. A transmissão pode ocorrer através de um vetor Culicoides spp., do sêmen ou por via transplacentária. O diagnóstico é realizado através de transcrição reversa seguida de reação em cadeia da polimerase (RT-PCR) com kits comerciais disponíveis, ou através de exames sorológicos de imunofluorescência indireta e prova de virusneutralização. Como ainda não existe um tratamento eficaz, torna-se importante as medidas de prevenção e controle, atuando no combate de vetores ou na vacinação do rebanho. Devido à importância desta doença no cenário mundial, é relevante o incentivo em pesquisas neste tema, além de conscientização das pessoas envolvidas na produção de ruminantes no Brasil.
\end{abstract}

Palavras-chave: aborto; Orthobunyavirus, malformações congênitas, SBV.

\begin{abstract}
The objective was to gather relevant information on the Schmallenberg, which is an emerging viral disease on the European continent, which was first identified in Germany. Abortions, fetal malformations, and perinatal deaths are also associated with the virus, mainly arthrogryposis and changes in the central nervous system. Transmission may occur via a vector, Culicoides spp., semen or transplacental transmission. Diagnosis is made via reverse-transcriptase polymerase chain reaction (RT-PCR) with commercial kits available, or indirect immunofluorescence and virus neutralization tests. As there is still no effective treatment, prevention and control measures are important, acting in the fight against vectors or in the vaccination of the herd. Due to the importance of this disease in the world scenario, it is relevant to encourage research on this topic, in addition to raising the awareness of the people involved in the production of ruminants in Brazil.
\end{abstract}

Keywords: abortion; Orthobunyavirus, congenital malformations, SBV.

\section{Introdução}

Schmallenberg orthobunyavirus (SBV), conhecido comumente como vírus de Schmallenberg, é um vírus envelopado de RNA de cadeia simples, genoma segmentado de sentido negativo, que pertencente à família Peribunyaviridae, do gênero Orthobunyavirus, e faz parte do sorogrupo Simbu (ICTV, 2020). Os membros do gênero Orthobunyavirus são amplamente distribuídos na Ásia, África e Oceania, no entanto, o sorogrupo Simbu nunca havia sido detectado anteriormente na Europa, sendo o SBV o primeiro Orthobunyavirus no continente europeu (Hoffmann et al., 2012).

Os primeiros relatos de casos de SBV surgiram em agosto de 2011, na Alemanha, onde 
observaram-se vacas leiteiras adultas com uma doença de período curto e de sinais inespecíficos, onde não se obteve diagnóstico definitivo a princípio. Em novembro de 2011 o Instituto Friedrich Loeffler detectou pela primeira vez o vírus, a partir de amostras de sangue colhidas de três vacas clinicamente doentes em outubro de 2011. O vírus recebeu tal nome devido à localização da fazenda onde as vacas estavam, na cidade de Schmallenberg (Alemanha) (Hoffmann et al., 2012).

No mesmo ano, 2011, o SBV foi detectado na Holanda e Bélgica (Hoffmann et al., 2012), seguido pela Itália, França, Luxemburgo e Reino Unido (janeiro a fevereiro de 2012), Dinamarca e Espanha (março a junho de 2012), e de julho a dezembro de 2012 na Irlanda, Suíça, Áustria, República Tcheca, Polônia, Letônia, Estônia, Suécia, Finlândia, Eslovênia e na Hungria (Afonso et al., 2014). É evidente o caráter endêmico do $\mathrm{SBV}$, visto sua rápida disseminação pela Europa Ocidental e sua presença confirmada em 27 países europeus até setembro de 2013 (Wernike et al., 2014).

Até o momento o RNA do SBV foi detectado em bovinos, ovinos, caprinos, bisões, veados, mouflons (ovinos selvagens) e cães; e anticorpos através de exame sorológico em lhamas, cervos, alpacas, javalis e vários outros ruminantes selvagens e alguns animais de zoológicos (OIE, 2017).

\section{Desenvolvimento}

A transmissão ocorre predominantemente através de um inseto vetor Culicoides spp. (Hoffmann et al., 2012; OMS, 2013), de caráter sazonal, o que sugere casos em períodos específicos do ano, como nos meses de maio a novembro (Lievaart-Peterson et al., 2012). A transmissão direta de animal para animal não foi relatada até o momento (OIE, 2017).

Estudos apontam o Culicoides obsoletus é o vetor mais provável, devido a grande abundância de RNA SBV em mosquitos positivos em áreas de surtos, indicando ativa circulação deste vírus. Aliado a isto, resultados confirmam a importância epizoológica também de $C$. scoticus, $C$. punctatus, C. chiopterus, $C$. dewulfi e C. imicola (Goffredo et al., 2013; Larska et al., 2013; Ségard et al., 2018).

Ainda não há relatos das espécies de mosquitos do gênero Culicoides relacionados à transmissão do SBV no Brasil. No território brasileiro, o Culicoides insignis é a espécie mais abundante, principalmente no período chuvoso, estando presente também as espécies Culicoides paucienfuscatus Barbosa, Culicoides diabolicus Hoffman, Culicoides leopoldoi Ortiz, Culicoides duartei Tavares e Luna Dias, e Culicoides contubernalis (Carvalho e Silva, 2014; Carvalho et al., 2016). Apesar da diferença de populações de Culicoides, a sua abundância é um fator importante para estudos de vigilância epidemiológica no Brasil.

Através do programa de vigilância entomológica da febre catarral ovina na Itália, foi possível analisar em 2013, coleções de insetos armazenados desde 2001, e assim verificar a presença do vírus SBV nos Culicoides spp. do país. Com isso, comprovou-se que apesar do primeiro caso de Schmallenberg na Itália ser relatado em fevereiro de 2012, o vírus estava circulando em pelo menos 3 províncias italianas desde o início de setembro de 2011, com cerca de 5 meses antes e 40 quilômetros distantes do primeiro surto (Goffredo et al., 2013).

Uma vez que é pouco conhecido o ciclo de vida do SBV, a transmissão direta e/ou a atividade de outros possíveis vetores, tais como carrapatos e outros gêneros de mosquitos (OMS, 2013), podem desempenhar um papel importante e não podem ser excluídos, enfatizando a necessidade de se ter um bom programa de vigilância epidemiológica em locais de risco, indicando quando potenciais vetores estão se movendo para determinada área ou se os números estão aumentando (Goffredo et al., 2013).

Análise efetuada nos Países Baixos revelou que os parâmetros de fertilidade foram significativamente afetados em rebanhos leiteiros no ano de 2011, em comparação aos dois anos anteriores. Já na Alemanha foi constatada uma elevação da necessidade de repetições de inseminação artificial para emprenhar os animais no mesmo período avaliado, apoiando a hipótese de que o SBV tem impacto negativo sobre o desempenho reprodutivo no gado leiteiro. Também foi descrita uma significativa redução da produção diária de leite por vaca, sendo estimada entre agosto a novembro de 2011 uma perda total de 6,44 $\mathrm{Kg}$ por vaca nos rebanhos leiteiros associada ao SBV. Entretanto, nos meses de agosto a setembro de 2011 verificou-se uma perda de $9,1 \mathrm{Kg}$ por vaca nos rebanhos leiteiros e de $15,1 \mathrm{Kg}$ por vaca de rebanhos específicos que notificaram a presença do SBV nos bovinos (Veldhuis et al., 2014). 
A primeira detecção do SBV no sêmen foi na espécie bovina, a partir de transcrição reversa seguida de reação em cadeia da polimerase (RTPCR) de amostras de centros de reprodução na Alemanha. Porém, sua presença não implica necessariamente a transmissão venérea ou subsequente in vitro ou in vivo (Hoffmann et al., 2013). Até o momento é desconhecido o potencial de transmissão por reprodução natural ou inseminação artificial (OIE, 2017), todavia, para garantir o comércio seguro de sêmen, este deve ser colhido e tratado em centros de coleta aprovados e controlados, obtidos a partir de animais cujo estado de saúde seja seguro e que não tenha risco de propagação de qualquer doença através da inseminação artificial (Ponsart et al., 2014).

Um estudo com ejaculado de touros naturalmente infectados com SBV observou a infecciosidade do sêmen, uma vez que amostras foram inoculadas em ratos por via subcutânea e após quatro dias, utilizando-se amostras de sangue, foram encontrados altos níveis de RNA de SBV neles. Com duas a três semanas constatou-se a presença de anticorpos específicos para SBV, através do teste de ELISA (Ponsart et al., 2014).

A transmissão vertical através da placenta foi comprovada, de modo que o vírus pode persistir no feto e resultar no nascimento de neonatos positivos (OIE, 2017). Em analogia com outros Orthobunyavirus, acredita-se que se a infecção ocorrer no início da prenhez, um número maior de mortes fetais ocorrerá, assim como um aumento na taxa de retorno ao cio das fêmeas. Caso a infecção ocorra entre os $25^{\circ}$ e $50^{\circ}$ dias da gestação, podem ocorrer malformações do sistema nervoso central, assim como desenvolvimento muscular prejudicado. Após o $76^{\circ}$ dia, quando os fetos já são imunocompetentes, estes podem não apresentar sinais clínicos de infecção durante a gestação ou após o nascimento (Lievaart-Peterson et al., 2012).

É recomendado pela OIE que embriões devem ser coletados de animais clinicamente saudáveis e medidas de segurança devem ser seguidas, visto que até o conhecimento atual, o risco em animais soronegativos é insignificante. Animais doadores soropositivos e RT-PCR negativos devem ser considerados com risco negligenciável (OMS, 2013).

Os animais infectados com SBV apresentam sinais inaparentes e inespecíficos, sendo que bovinos adultos têm exibido uma forma leve da doença, incluindo hipertermia (acima de $40^{\circ} \mathrm{C}$ ), redução da produção de leite e diarreia, recuperando-se dentro de alguns dias (Hoffmann et al., 2012; OIE, 2017). Deve-se suspeitar de abortos, malformações fetais e mortes perinatais, que também são sinais clínicos de SBV. Os achados de necropsia mais observados são artrogripose de membros anteriores e posteriores, podendo estar presente também braquignatismo inferior, curvatura de coluna vertebral (torcicolo, cifose, lordose ou escoliose) e defeitos músculoesqueléticos. Malformações de várias regiões do sistema nervoso central, como hidrocefalia, macrocefalia ou hipoplasia refletem a natureza neurotrópica do SBV e correspondem com alterações esqueléticas axiais e apendiculares através do eixo neuromuscular (Herder et al., 2012; Luttikholt et al., 2014; OIE, 2017).

Para detecção de infecções agudas e crônicas em animais vivos, pode-se utilizar amostras de sangue com anticoagulante EDTA ou soro para realização do teste ELISA, de imunofluorescência indireta, ou de virusneutralização, com kits comerciais disponíveis (OIE, 2017). Testes de ELISA para anticorpos contra SBV também podem ser realizados com amostras de leite (Daly et al., 2015).

O uso de protocolos de ELISA in-house, demonstra uma especificidade e sensibilidade comparáveis ao teste de neutralização de vírus, e também mostra uma maior sensibilidade, em comparação ao ELISA indireto disponível no mercado, fornecendo um método de detecção sorológica rápida que seria adequado para vigilância e triagem do SBV em grandes escalas (Naslund et al., 2014).

O SBV também pode ser identificado através da realização do RT-PCR em tempo real, predominantemente utilizada com kits comerciais disponíveis e os resultados positivos devem ser confirmados por sequenciamento (Hoffmann et al., 2012). O RNA viral é detectável por menos de uma semana após a infecção (Wernike et al., 2013a). Também pode ser realizado o isolamento do vírus em cultura celular de inseto (KC), de células de hamster (BHK) ou de células renais de macaco (VERO) (Zhang et al., 2015; OIE, 2017).

De neonatos ruminantes mortos, o tronco cerebral é a amostra mais adequada para detecção de SBV por RT-PCR (De Regge et al., 2013), porém pode-se também utilizar amostras de cérebro, medula espinhal, líquido amniótico, líquido pericárdico, sangue, placenta, mecônio (OIE, 2017), cordão umbilical, cartilagem da costela, baço (Bilk et al., 2012), pulmão, rim, 
linfonodos mandibulares e mesentéricos, ou em esfregaços fecais, orais e nasais (Wernike et al., 2013b).

Como até o momento não há relatos de tratamento para SBV, é importante a instituição de medidas de prevenção e controle para diminuir a incidência de casos (OIE, 2017). Foi aconselhado aos produtores europeus a tratarem seus rebanhos contra parasitas externos e manter os animais protegidos contra os mosquitos a partir de seis semanas antes do período de acasalamento até o final deste. Caso essas medidas não fossem possíveis de aplicar no rebanho, recomendou-se reagendar o período de acasalamento para meses em que a densidade da população de Culicoides spp. seja menor, que nas condições alemãs corresponderia aos meses de outubro e novembro (Helmer et al., 2013; OIE, 2017).

Considerado uma nova ameaça ao território brasileiro, tendo em vista que o SBV está amplamente distribuído nos países da Europa, provocando significativas perdas econômicas por meio da diminuição da produtividade. Mesmo não existindo estudos sobre a presença do vírus ou investigação sobre anticorpos contra este agente no nosso país, as evidências científicas disponíveis dão sustento à adoção de medidas de mitigação de risco capazes de prevenir a introdução da doença nos Estados Partes do Mercado Comum do Sul (MERCOSUL), no caso de importação de ruminantes procedentes de países que registraram casos positivos (BRASIL, 2018).

A Instrução Normativa $n^{\circ} 33$, de 27 de abril de 2020 estabelece que toda importação de embriões caprinos ao MERCOSUL deve estar acompanhada de Certificado Veterinário Internacional, emitido pela Autoridade Veterinária do país exportador, incluindo as garantias zoossanitárias, para sua prévia autorização pelo Estado Parte importador (BRASIL, 2020). Deverão ser cumpridos os "Requisitos zoossanitários adicionais dos Estados Partes para a importação de sêmen e embriões de ruminantes com relação à doença de Schmallenberg", conforme o estabelecido na Resolução GMC No 45/14, suas modificativas e/ou complementares (BRASIL, 2020).

O país de origem deverá certificar que os animais sejam originários de um país onde nunca se tenham registrado casos de SBV, ou, no caso de que sejam originários de países onde se tenham registrado casos: I) provenham de um estabelecimento onde não tenha havido evidências clínicas nem sorológicas da doença durante pelo menos os seis meses anteriores ao início da quarentena; II) tenham sido submetidos a uma quarentena sob supervisão oficial em um estabelecimento onde não tenha ocorrido evidências clínicas nem sorológicas da doença, assim como em um raio de $10 \mathrm{Km}$ deste, durante os trinta dias prévios ao embarque; III) tenham sido submetidos a uma prova de ELISA, ou imunofluorescência indireta, ou virusneutralização com resultado negativo realizada pelo menos 21 dias posterior ao início da quarentena; IV) tenham sido protegidos contra vetores em todo momento, desde o início da quarentena até seu embarque no ponto de saída do país exportador (BRASIL, 2018).

As provas diagnósticas devem ser realizadas em laboratórios oficiais, habilitados, credenciados ou reconhecidos pela Autoridade Veterinária do país de origem dos embriões, que devem ser realizadas de acordo com o Manual Terrestre da Organização Mundial de Saúde Animal (BRASIL, 2020).

Embora existam vacinas eficazes e seguras, o custo da vacinação para a indústria da pecuária contra o SBV é relativamente alto, visto as baixas margens de lucro por animal nos setores da criação. Bons dados sobre a distribuição e impacto do SBV são importantes para permitir que produtores tomem suas decisões (Roberts et al., 2012). As vacinas inativadas estão comercialmente disponíveis em alguns países, sendo que todas as vacinas existentes atualmente apresentam imunidade após três semanas da vacinação (OIE, 2017).

Existem poucos dados sobre a duração da imunidade em bovinos, que sugerem que a imunidade dura pelo menos um ano após a infecção natural, e nenhum sobre a duração da imunidade em ovinos. Os dados sobre imunidade por períodos mais longos ainda não estão disponíveis (EFSA, 2014).

A vacina Bovilis SBV $^{\circledR}$ (MSD ANIMAL HEALTH), autorizada pela Veterinary Medicines Directorate no Reino Unido, foi a primeira vacina desenvolvida comercialmente para imunização de bovinos e ovinos contra o SBV (MSD ANIMAL HEALTH, 2013). SBVvax ${ }^{\circledR}$ (MERIAL, 2017) e Zulvac SBV ${ }^{\circledR}$ (EMA, 2014) também estão disponíveis atualmente no mercado.

Até o momento considera-se o vírus como não-zoonótico (OIE, 2017) e o risco de transmissão para o homem e os animais através da carne e do leite insignificante, porém como precaução é 
recomendado que só se deve utilizar animais clinicamente saudáveis para retirada do leite ou abate e consumo da carne (OMS, 2013), e preconiza-se a utilização de medidas de proteção e higiene para os humanos ao entrar em contato com um rebanho ou com um material de aborto suspeito (ECDC, 2012).

O Instituto Robert Koch (Alemanha), em 2012, testou criadores de ovinos que viviam em uma área epidêmica e tiveram contato direto com material de ovinos e cordeiros infectados com SBV e não obtiveram evidência de aumento da frequência de sintomas clínicos incomuns nas pessoas, e as amostras de sangue humanas apresentaram resultados negativos para SBV. Outro estudo semelhante realizado no mesmo ano na Holanda, apresentou também resultados negativos em trabalhadores de fazendas e veterinários expostos a rebanhos infectados com SBV, confirmando que é muito improvável que o SBV represente um risco para os seres humanos (ECDC, 2012).

\section{Considerações Finais}

Schmallenberg é uma doença viral recente, que apesar de ter surgido há apenas nove anos, tem sido tema de várias pesquisas, permitindo conhecer sua epidemiologia, transmissão e impactos na produção animal, além de incluí-la na lista de diagnósticos diferenciais para febre, diminuição da produção leiteira, diarreia, abortos, malformações fetais e mortes perinatais em ruminantes. Também foi possível desenvolver diagnósticos sensíveis e específicos, e elencar métodos de profilaxia e controle, tal como a comercialização de vacinas.

É válido ressaltar a importância da conscientização mundial sobre o Schmallenberg para todas as pessoas envolvidas na criação de ruminantes, uma vez que, com a facilidade de comércio e transporte de animais, sêmen e embriões entre diversas regiões e até mesmo entre países, há um grande risco de infecção de rebanhos fora das áreas de risco europeia, sendo de extrema importância a execução de medidas de prevenção para evitar a introdução desta enfermidade no Brasil. Contudo, algumas questões ainda permanecem sem respostas, sendo necessários mais estudos, principalmente em relação à patogenia desta enfermidade e o desenvolvimento de um tratamento eficaz.

\section{Referências}

Afonso, A.; Abrahantes, J.C.; Conraths, F.; Veldhuis, A.; Elbers, A.; Roberts, H.; Van der Stede, Y.; Méroc, E.; Gache, K.; Richardson, J. The Schmallenberg virus epidemic in Europe 2011-2013. Preventive Veterinary Medicine, 116: 391-403, 2014.

Bilk, S.; Schulze, C.; Fischer, M.; Beer, M.; Hlinak, A.; Hoffmann, B. Organ distribution of Schmallenberg virus RBA in malformed newborn. Veterinary Microbiology, 159: 236238, 2012.

BRASIL. Ministério da Agricultura, Pecuária e Abastecimento/Gabinete do Ministro. Instrução Normativa $n^{0}$ 20, de 24 de abril de 2018. Diário Oficial da União (DOU), Edição 89, Seção 1, página 3, 2018.

BRASIL. Ministério da Agricultura, Pecuária e Abastecimento/Gabinete da Ministra. Instrução Normativa $n^{0}$ 33, de 27 de abril de 2020. Diário Oficial da União (DOU), Edição 81, Seção 1, pág. 18, 2020.

Carvalho, L.P.C.; Silva, F.S. Seasonal abundance of livestock-associated Culicoides species in northeastern Brazil. Medical and Veterinary Entomology, 28: 228-231, 2014.

Carvalho, L.P.C.; Pereira Júnior, A.M.; Farias, E.S.; Almeida, J.F.; Rodrigues, M.S.; Resadore, F.; Pessoa, F.A.C.; Medeiros, J.F. A study of Culicoides in Rondônia, in the Brazilian Amazon: species composition, relative abundance and potential vectors. Medical and Veterinary Entomology, 31(1): 117-122, 2016.

Daly, J.M.; King, B.; Tarlinton, R.A.; Gough, K.C.; Maddison, B.C.; Blowey, R. Comparison of Schmallenberg virus antibody levels detected in milk and serum from individual cows. BMC Veterinary Research, 11(56): 1-4, 2015.

De Regge, N.; van den Berg, T.; Georges, L.; Cay, B. Diagnosis of Schmallenberg virus infection in malformed lambs and calves and first indications for virus clearance in the fetus. Veterinary Microbiology, 162: 595-600, 2013. EFSA - European Food Safety Authority, Schamallenberg virus: Stat of art. EFSA Journal, 12(5): 3681, 2014.

EMA - European Medicines Agency. Zulvac SBV. 2015. Disponível em: <http://www.ema.europa.eu/docs/en_GB/docu ment_library/EPAR_Summary_for_the_publi c/veterinary/002781/WC500183575.pdf >. Acesso em: 20 jan. 2018. 
ECDC - European Centre For Disease Prevention and Control. Joint Risk Assessment: New Orthobunyavirus isolated from infected cattle and small livestock - potential implications for human health, 2012. Disponível em: $<$ https://ecdc.europa.eu/sites/portal/files/media/ en/publications/Publications/TER-Joint-

ECDC-RIVM-RKI-Rapid-Risk-Assessment-

Schmallenberg-virus-May-2012.pdf>. Acesso em: 15 mar. 2018.

ICTV - International Committee on Taxonomy of Viruses. ICTV Taxonomy history: Schmallenberg orthobunyavirus, 2020. Disponível em: <https://talk.ictvonline.org/taxonomy/p/taxono my-history?taxnode_id=201900126>. Acesso em: 16 set. 2020.

Goffredo, M.; Monaco, F.; Capelli, G.; Quaglia, M.; Federici, V.; Catalani, M.; Montarsi, F.; Polci, C.; Pinoni, C.; Calistri, P.; Savini, G. Schmallenberg virus in Italy: a retrospective survey in Culicoides stored during the bluetongue Italian surveillance program. Preventive Veterinary Medicine, 111: 230236, 2013.

Helmer, C.; Eibach, R.; Tegtmeyer, P.C.; HumannZiehank, E.; Ganter, M. Survey of Schmallenberg virus (SBV) infection in German goat flocks. Epidemiology \& Infection, 141: 2335-2345, 2013.

Herder, V.; Wohlsein, P.; Peters, M.; Hansmann, F.; Baumgartner, M. Salient lessons in domestic ruminants infected with the emerging so called Schmallenberg virus in Germany. Veterinary Pathology, 49(4): 588-591, 2012.

Hoffmann, B.; Scheuch, M.; Hoper, D.; Jungblut, R.; Holsteg, M.; Schirrmeier, H.; Eschbaurmer, M.; Goller, K.V.; Wernike, K.; Fischer, M.; Breithaupt, A.; Mettenleiter, T.C.; Beer, M. Novel orthobunyavirus in cattle, Europe, 2011. Emerging Infectious Diseases, 18(3): 469472, 2012.

Hoffmann, B.; Schulz, C.; Beer, M. First detection of Schmallenberg virus RNA in bovine semen, Germany, 2012. Veterinary Microbiology, 167: 289-295, 2013.

Larska, M.; Lechowski, L.; Grochowska, M.; Zmudzinski, J.F. Detection of the Schmallenberg virus in nulliparous Culicoides obsoletus/scoticus complex and C. punctatus The possibility of transovarial virus transmission in the midge population and of a new vector. Veterinary Microbiology, 166(34): 467-473, 2013.

Lievaart-Peterson, K.; Luttikholt, S.J.M.; Van den Brom, R.; Vellema, P. Schmallenberg virus infection in small ruminants - First review of the situation and prospects in Northern Europe. Small Ruminants Research, 106: 71-76, 2012.

Luttikholt, S.; Veldhuis, A.; Van den Brom, R.; Moll, L.; Lievaart-Peterson, K.; Peperkamp, K.; Van Schaik, G.; Vellema, P. Risk Factors for Malformations and Impact on Reproductive Performance and Mortality Rates of Schmallenberg Virus in Sheep Flocks in the Netherlands. Plos One, 9: 1-8, 2014.

Merial. SBVvax prevents viremia against Schmallenberg virus in both sheep and cattle, 2013. Disponível em: $<$ http://merial.com/en/content-pages/pressreleases/merial-receives-approval-for-newvaccine-to-prevent-schmallenberg-disease-inlivestock>. Acesso em: 10 set. 2017.

MSD Animal Health. Bovilis SBV. 2013. Disponível em: <http://www.parkvets.com/bovilis.pdf>. Acesso em: 20 jan. 2017.

Naslund, K.; Blomqvist, G.; Vernersson, C.; Zientara, S.; Bréard, E.; Valarcher, J.F. Development and evaluation of an indirect enzyme-linked immunosorbent assay for serological detection of Schmallenberg virus antibodies in ruminants using whole virus antigen. Acta Veterinaria Scandinavica, 56(71): 1-29, 2014.

OIE - World Organisation for Animal Health. Schmallenberg virus - OIE Technical Factsheet, 2017. Disponível em: <http://www.oie.int/fileadmin/Home/eng/Our_ scientific_expertise/docs/pdf/A_Schmallenberg _virus.pdf.> Acesso em: 20 dez. 2017.

OMS - Organização Mundial de Sanidade Animal. Virus de Schmallenberg - Ficha técnica de La OIE, 2013. Disponível em: $<$ http://www.oie.int/fileadmin/Home/esp/Our_ scientific_expertise/docs/pdf/E_Schmallenberg _virus.pdf >. Acesso em: 25 out. 2017.

Ponsart, C.; Pozzi, N.; Bréard, E.; Catinot, V.; Viard, G.; Sailleau, C.; Viarouge, C.; Gouzil, J.; Beer, M.; Zientara, S.; Vitour, D. Evidence of excretion of Schmallenberg virus in bull semen. Veterinary Research, 45(37): 1-6, 2014.

Roberts, H.; Middlemiss, C.; Gibbens, N. Schmallenberg virus: Responding to the 
challenge. The Veterinary Journal, 194: 1-2, 2012.

Ségard A.; Gardès, L.; Jacquier, E.; Grillet, C.; Mathieu, B.; Rakotoarivony, I.; Setier-Rio, M.L.; Chavernac, D.; Cetre-Sossah, C.; Balenghien, T.; Garros, C. Schmallenberg virus in Culicoides Latreille (Diptera: Ceratopogonidae) populations in France during 2011-2012 outbreak. Transboundary Emerging Diseases, 65(1): 1-10, 2018.

Veldhuis, A.M.B.; Santman-Berends, I.M.G.A.; Gethmann, J.M.; Mars, M.H.; Van Wuyckhuise, L.; Vellema, P.; Holsteg, M.; Horeth-Bontgen, D.; Conraths, F.J.; Van Schaik, G. Schmallenberg virus epidemic: Impact on Milk production, reproductive and mortality in dairy cattle in the Netherlands and Kleve district, Germany. Preventive Veterinary Medicine, 116(4): 412-422, 2014.

Wernike, K.; Eschbaumer, M.; Schirrmeier, H.; Blohm, U.; Breithaupt, A.; Hoffmann, B.; Beer, M. Oral exposure, reinfection and cellular immunity to Schmallenberg virus in cattle. Veterinary Microbiology, 165, 2013a.

Wernike, K.; Hoffmann, B.; Bréard, E.; Botner, A.; Ponsart, C.; Zientara, S.; Lohse, L.; Pozzi, N.; Viarouge, C.; Sarradin, P.; Leroux-Barc, C.; Riou, M.; Laloy, E.; Breithaupt, A.; Beer, M. Schmallenberg virus experimental infection of sheep. Veterinary Microbiology, 166: 461466, 2013b.

Wernike, K.; Conraths, F.; Zanella, G.; Granzow, H.; Gache, K.; Schirrmeier, H.; Valas, S.; Staubach, C.; Marianneau, P.; Kraatz, F.; Horeth-Bontgen, D.; Reimann, I.; Zientara, S.; Beer, M. Schmallenberg virus - Two years of experiences. Preventive Veterinary Medicine, 116: 423-434, 2014.

Zhang, Y.; Wu, S.; Song, S.; Lv, J.; Feng, C.; Lin, $\mathrm{X}$. Preparation and characterization of a stable BHK-21 cell line constitutively expressing the Schmallenberg virus nucleocapsid protein. Molecular and Cellular Probes, 29: 244-253, 2015 . 